\title{
PARP Inhibitors in Prostate Cancer
}

\author{
KABIR GREWAL ${ }^{1}$, KAYANAAT GREWAL ${ }^{2}$ and IMAD A. TABBARA ${ }^{3}$ \\ ${ }^{1}$ Florida State University College of Medicine, Tallahassee, FL, U.S.A.; \\ ${ }^{2}$ George Mason University, Fairfax, VA, U.S.A.; \\ ${ }^{3}$ George Washington University School of Medicine, Washington, DC, U.S.A.
}

\begin{abstract}
Treatment of metastatic prostate cancer has evolved significantly over the past decade. Palliative therapy has, historically, consisted of androgen deprivation, chemotherapy and different radiation therapy approaches. More recently, breakthrough therapy with the use of poly-ADP-ribose polymerase (PARP) inhibitors has led to significant improvement in the outcome of patients with metastatic prostate cancer who harbor certain genetic mutations. This concise review focuses on the 3 PARP inhibitors that have shown activity in metastatic prostate cancer.
\end{abstract}

Prostate cancer $(\mathrm{PCa})$ is the second most frequent cancer diagnosed in men and the fifth leading cause of death worldwide (1). The average American male has a 12 percent lifetime risk of being diagnosed with $\mathrm{PCa}$ (1). The incidence and severity of $\mathrm{PCa}$ is strongly related to age and is more prevalent among African American men (2). Although there is not yet any substantial evidence regarding the prevention of this malignancy, it is possible to lower its risk by limiting high-fat foods, increasing the consumption of fruits and vegetables, and exercising regularly (2).

The American Cancer Society (ACS) recommends that screening for PCa should be occurring at the age of 50 for average risk men, and at the age of 45 for either African American men or those with a family history of PCa (3). The typical screening process includes a prostate-specific antigen (PSA) blood test and sometimes a digital rectal exam (DRE) as

This article is freely accessible online.

Correspondence to: Imad A. Tabbara, MD, FACP, Professor of Medicine, George Washington University, 2150 Pennsylvania Avenue, NW, Suite 1-200, Washington, DC 20037, U.S.A. Tel: +1 2027412478, Fax: +1 2027412487, e-mail: itabbara@mfa.gwu.edu

Key Words: PARP, prostate cancer, prostate adenocarcinoma, $\mathrm{PCa}$, MCRPC, review. well (3). A prostate biopsy can be obtained in order to confirm the diagnosis as well as prognosis (3). If the biopsy returns positive, the Gleason score system is used to grade the metastatic ability and overall severity of the cancer (4). Further tests are then conducted to determine the extent of the disease (5).

There are currently many different treatment options for men who are diagnosed with PCa. Factors such as stage of the disease, patient age, underlying health issues, and past treatment, are considered when making clinical decisions. Surgical resection tends to be a viable solution for healthy patients whose cancer has not metastasized beyond the prostate gland (5). Radiation therapy is also often used to treat localized forms of $\mathrm{PCa}$ (6). On the other hand, hormone therapy, known as androgen ablation or androgen deprivation therapy, is the first line of treatment for advanced, metastatic prostate cancer (7). Chemotherapy and immunotherapy are other systemic treatments that can be used for both localized and metastatic forms of PCa (6). Some of these different treatment types can be administered in conjugation with each other.

Over the last few years, a new approach called targeted therapy has shown great promise in treating PCa. This type of treatment targets tumor specific genes, proteins, or the tissue environment that contributes to cancer growth and survival (6). The goal is to effectively block the growth and spread of cancer cells while limiting damage to healthy cells. Among different forms of targeted therapy, poly-ADP-ribose polymerase (PARP) inhibitors are one of the most notable and promising drug classes (6). The FDA recently approved the first two PARP inhibitors for the treatment of metastatic $\mathrm{PCa}$; the general treatment protocol for prostate cancer may soon be revolutionized (8).

\section{PARP Inhibitors}

Poly-ADP-ribose polymerases (PARPs) are a family of enzymes that catalyze the transfer of ADP-ribose to target proteins (9). PARPs play a crucial role in various cellular processes including transcription, replication, recombination, cell proliferation, and most notably, DNA repair $(10,11)$. 
Evidence for the importance of PARP in DNA repair comes from the finding that both DNA damaging agents and radiation-induced DNA damage caused increased PARP activity (11).

PARP1, the best-known enzyme in this family, plays a pivotal role in the detection and repair of DNA breaks (12, 13). Upon detecting and subsequently binding to sites of single strand DNA damage, PARP1 synthesizes poly-ADPribose (PAR) and transfers it to acceptor proteins (9). It then recruits other important repair enzymes to the damaged DNA site (14). PARP1 has also been shown to be a rate limiting step in both base-excision repair (BER) and nucleotideexcision repair (NER) $(15,16)$. Since studies have shown that BER and NER are key pathways that enable the repair of DNA damage caused by certain alkylating and chemotherapeutic agents, the upregulation of PARP is one of several mechanisms by which tumor cells can gain resistance to cancer therapy (10). Counter studies have also shown that the treatment of $P A R P^{-/-}$mice by either alkylating agents or $\gamma$-irradiation result in high genomic instability and an extreme sensitivity to both agents (17). Thus, because PARPs are integral to DNA repair, the down-regulation or blocking of PARP has the potential to increase the susceptibility of tumor cells to various forms of anti-cancer therapy.

Since PARP has an important role in DNA repair, the inhibition of PARP results in increased genomic instability as well as the accumulation of damaged cells in cell cycle arrest (18). This has been demonstrated by experiments that show how ADP-ribosylation reactions are used to repair damaged DNA as well as to progress through the G2 and M phases of the cell cycle (18). Thus, PARP inhibition leads to cells that are more vulnerable to DNA damage.

Studies have shown that DNA damaging agents lead to rapid apoptosis in $\mathrm{PARP}^{-/}$cells (17). Although, as noted earlier, $\mathrm{PARP}^{-/-}$mice were shown to be extremely sensitive to DNA damaging agents, the same PARP deficient mice remained healthy under control conditions (17). The viability of the $\mathrm{PARP}^{-/-}$mice suggests that PARP is relatively dispensable for normal activity but is an essential survival factor for DNA damage (17). These are some of the characteristics that make PARP inhibition an attractive approach to use for the treatment of cancer in general, and specifically in $\mathrm{PCa}$.

\section{PARP Inhibitors and Prostate Cancer}

Multiple studies have reported a strong association of frequent deleterious germline mutations in DNA Damage Repair (DDR) genes with advanced $\mathrm{PCa}$, which defines the basis for the use of PARP inhibitors to treat this disease (9). DDR alterations are present in nearly $23 \%$ of all metastatic castration-resistant prostate cancer (mCRPC) (19). These mutations often involve the $B R C A 1 / B R C A 2$ genes, as well as the PTEN gene $(20,21)$. These genes are involved in DNA damage repair as well as in tumor suppression (22). They are also crucial to the homologous recombination repair (HRR) pathway (23). Due to a reduced ability to repair DNA and regulate cell growth, patients with inherited $B R C A 2$ mutations are five times more likely to be diagnosed with prostate cancer than the general population (24). BRCA mutations are also more frequently associated with prostate cancer of a high grade, high stage, with increased nodal involvement, and metastasis (20). Additionally, 20\% of all prostate cancers involve deficient PTEN expression (21). Since BRCA plays a vital role in homologous recombination, researchers believe that $B R C A$ mutant cells depend more heavily on the PARP-associated repair pathway (9). Various experiments have even shown evidence for the upregulation of PARP activity in certain types of cancer cells (10). This has been the rationale behind many recent clinical trials (9).

Since tumor cells with DDR gene mutations rely more heavily on PARP to correct DNA breaks and mismatches, the inhibition of PARP should make these cancerous cells more susceptible to chemotherapy and other treatment options (14). Further, PARP inhibition might even be potent as a single anti-cancer agent. Studies have shown that HRR defective cells are hypersensitive to PARP inhibition alone (25). Recent results have also shown that PARP inhibition in $B R C A$ deficient patients with ovarian cancer led to significantly less cancer progression and mortality (26). These results have encouraged further research into PARP inhibition for PCa therapy.

In May 2020, the Food and Drug Administration (FDA) officially approved the first two PARP inhibitors, Rucaparib and Olaparib, for the treatment of prostate cancer (8). Table I highlights the key developments of the different PARP Inhibitors in the treatment of PCa.

\section{Rucaparib}

On May 15, 2020, the FDA granted accelerated approval to Rucaparib (RUBRACA, Clovis Oncology) for patients with deleterious BRCA mutation (germline and/or somatic)associated metastatic castration resistant prostate cancer (mCRPC) who have already been treated with both androgen receptor-directed therapy and taxane-based chemotherapy (27). Two of the recent clinical trials that have paved the way for Rucaparib's FDA approval include TRITON2 and TRITON3 trials $(27,28)$.

TRITON2 is an ongoing phase II trial evaluating $600 \mathrm{mg}$ doses of Rucaparib in patients with $\mathrm{MCRPC}$ and an alteration in BRCA1/BRCA2, ATM, CKD12, or another prespecified DDR gene (27). Eligible patients have already progressed on prior androgen receptor directed therapy and taxane-based chemotherapy. Preliminary results show that among patients 
Table I. PARP inhibitors examined for the treatment of prostate cancer.

\begin{tabular}{lll}
\hline & Rucaparib (FDA approved) & \\
\hline Clinical trial name & Primary objective & Takeaways (If any) \\
\hline $\begin{array}{l}\text { TRITON2 (NCT02952534) } \\
\text { - Phase II }\end{array}$ & To study how patients with mCRPC and an & $-43.9 \%$ ORR in BRCA mutation patients with mCRPC \\
- 2016-Present & HRR gene deficiency respond to & $-52 \%$ of $B R C A$ mutation patients had decreased PSA \\
- Clovis Oncology & Rucaparib treatment. & - Less substantial responses in patients with \\
& & other mutations \\
TRITON3 (NCT02975934) & & \\
- Phase III & To study the effectiveness of Rucaparib in & - Aims to build on TRITON2 \\
- 2017-Present & treating patients with $B R C A$ or $A T M$ gene & - Results pending \\
- Clovis Oncology & mutations who have not yet undergone & \\
& chemotherapy. &
\end{tabular}

Olaparib (FDA approved)

PROfound (NCT02987543)

- Phase III

- Completed (2016-2020)

- AstraZeneca

TOPARP (NCT01682772)

- Phase II

- Completed (2012-2019)

- Institute of Cancer Research, United Kingdom

PROpel (NCT03732820)

- Phase III

- 2018-Present

- AstraZeneca

KEYLYNK (NCT03834519)

- Phase III

- 2019-Present

- Merck Sharp \& Dohme Corp.
To test the efficacy of Olaparib as a single therapy for mCRPC in patients who had already received hormonal therapy.

To evaluate the anti-tumor activity of Olaparib in mCRPC as well as to identify predictive biomarkers.
- Among patients with BRCA or ATM mutations, Olaparib led to increased survival and decreased cancer progression as compared to hormonal therapy

- Olaparib has significant activity against mCRPC in patients with DDR mutations including $B R C A$, ATM, CDK12, and PALB2

To evaluate the efficacy and safety of using - Results pending Olaparib alongside abiraterone in treating patients with mCRPC.

To study the efficacy of Olaparib alongside pembrolizumab in the treatment of patients

Results pending with mCRPC.

Niraparib (Pending approval)

GALAHAD (NCT02854436)

- Phase II

- 2016-Present

- Janssen Research \& Development
To assess the efficacy, safety, and pharmacokinetics of Niraparib in men with mCRPC and DNA repair mutations.
Interim results show that PARP inhibition with Niraparib is effective against mCRPC patients with $B R C A$ mutations with a $B R C A$ mutation, $43.9 \%$ had a confirmed objective response rate (ORR). Among these patients with a $B R C A$ mutation, $52 \%$ had a confirmed decrease in PSA levels. The ORR and PSA response to treatment were less substantial for patients with other genetic mutations (27).

TRITON3 is a phase III trial that aims to evaluate the effectiveness of Rucaparib as compared to second-line androgen receptor directed therapy and docetaxel in patients with mCRPC (28). All patients in this study have a $B R C A 1 / B R C A 2$ or $A T M$ mutation and have previously progressed on a first-line androgen receptor directed therapy. The patients included in this trial have not received chemotherapy. The aim of this study is to confirm the benefit seen in TRITON2.

\section{Olaparib}

On May 19, 2020, the FDA approved Olaparib (LYNPARZA, AstraZeneca) for the treatment of adult patients with germline or somatic HRR gene mutated metastatic castration resistant 
prostate cancer (mCRPC) who have progressed following prior treatment with enzalutamide (Xtandi) or abiraterone (Zytiga) (8). This was largely due to the success of the PROfound clinical trial series (29).

PROfound is a recently completed phase III trial that showed the efficacy of Olaparib as a single therapy for PCa (30). All participants in this trial had mCRPC and previously progressed following treatment with enzalutamide or abiraterone. Patients were divided into two separate cohorts. Cohort A $(\mathrm{n}=245)$ consisted of patients with at least one alteration in BRCA1, BRCA2, or ATM. Cohort B $(\mathrm{n}=142)$ consisted of patients with alterations in other HRR genes. Patients were randomly assigned to receive either Olaparib or to continue hormonal treatment with enzalutamide or abiraterone. Patients in Cohort A who received Olaparib had a greater median overall survival rate than those who continued to receive hormone therapy. Within Cohort A, the imaging-based cancer progression was also significantly lower in those who received Olaparib as compared to those who received a hormonal agent (30).

The ongoing phase III PROpel trial aims to take this approach further. This study will evaluate the efficacy and safety of Olaparib in combination with abiraterone in treating patients with mCRPC (30). This approach is being studied as a potential first-line therapy in mCRPC patients. This is similar to the ongoing KEYLYNK trial, which aims to assess the effectiveness of using Olaparib alongside pembrolizumab in the treatment of mCRPC patients who have failed to respond to abiraterone acetate, enzalutamide, and chemotherapy (30).

TOPARP is a recently completed phase II trial that aimed at evaluating the anti-tumor effect of Olaparib in MCRPC, determining the molecular signatures of tumor cells in responsive patients, and identifying the predictive biomarkers of positive response to Olaparib (18). This trial found that Olaparib has antitumor activity against mCRPC with DDR gene aberrations including BRCA1, BRCA2, ATM, $C D K 12$, and PALB2 (31).

\section{Niraparib}

Niraparib, although not yet FDA approved, is the other notable PARP inhibitor that has recently shown tremendous potential in treating PCa. The GALAHAD trial, in progress since 2016, aims to assess the efficacy, safety, and pharmacokinetics of Niraparib in men with mCRPC and DNA repair anomalies (32). The interim results of this study showed that Niraparib achieved an objective response rate of $38 \%$ and composite response rate of $65 \%$ in patients with a $B R C A$ mutation $(33,34)$. These preliminary results suggest that PARP inhibition through Niraparib may soon play an important role in the treatment of mCRPC patients with DNA repair mutations (33).

\section{Discussion}

PARP inhibitors have shown tremendous potential in treating mCRPC. This targeted therapy aims to limit metastatic growth by disrupting the process of DNA repair within cancer cells. This approach has shown to be especially effective in treating mCRPC patients with an underlying DDR gene mutation. This is likely because PARP is a more crucial DNA repair factor in patients carrying these mutations.

Moving forward, it will be crucial to test if PARP inhibition could be more effective if combined with other anti-cancer treatments. Future studies must also better determine the side effects and counter-indications of PARP inhibitors. It will also be imperative to study the likelihood of cancer recurrence years after treatment. Nonetheless, targeted therapy through PARP inhibition could have the ability to revolutionize the treatment of mCRPC.

\section{Conflicts of Interest}

The Authors declare no conflicts of interest in relation to this study.

\section{Authors' Contributions}

Kabir Grewal: Outline, literature research, article writing, edits, prepared table; Kayanaat Grewal: Outline, edits, citations; Imad A. Tabbara: Article idea, outline, edits, submission.

\section{References}

1 Hoffman RM: Clinical practice. Screening for prostate cancer. N Engl J Med 365(21): 2013-2019, 2011. PMID: 22029754. DOI: $10.1056 /$ nejmcp 1103642

2 Rawla P: Epidemiology of prostate cancer. World J Oncol 10(2): 63-89, 2019. PMID: 31068988. DOI: 10.14740/wjon1191

3 American Cancer Society Recommendations for Prostate Cancer Early Detection. American Cancer Society. 2019. Available at: https://www.cancer.org/cancer/prostate-cancer/detectiondiagnosis-staging/acs-recommendations.html [Last accessed August 8, 2020]

4 Tests to Diagnose and Stage Prostate Cancer. American Cancer Society. 2019. Available at: https://www.cancer.org/cancer/ prostate-cancer/detection-diagnosis-staging/how-diagnosed.html [Last accessed August 8, 2020]

5 Prostate Cancer Treatment (PDQ $\left.{ }^{\circledR}\right)-$ Patient Version. National Cancer Institute. June 26, 2020. Available at: https:// www.cancer.gov/types/prostate/patient/prostate-treatment-pdq [Last accessed August 8, 2020]

6 Prostate Cancer - Types of Treatment. Cancer.Net. May 21, 2020. Available at: https://www.cancer.net/cancer-types/prostatecancer/types-treatment [Last accessed August 30, 2020]

7 Advanced Prostate Cancer Treatment Options. WebMD. June 21, 2020. Available at: https://www.webmd.com/prostate-cancer/ guide/treating-advanced-prostate-cancer\#1 [Last accessed August 11, 2020] 
8 Kerr RR: FDA approves 2 PARP inhibitors for certain men with prostate cancer. Urology Times. May 21, 2020. Available at: https://www.urologytimes.com/view/fda-approves-2-parpinhibitors-certain-men-prostate-cancer [Last accessed August 11, 2020]

9 Virtanen V, Paunu K, Ahlskog JK, Varnai R, Sipeky C and Sundvall M: PARP inhibitors in prostate cancer - the preclinical rationale and current clinical development. Genes 10(8): 565, 2019. PMID: 31357527 . DOI: $10.3390 /$ genes 10080565

10 Morales J, Li L, Fattah FJ, Dong Y, Bey EA, Patel M, Gao J and Boothman DA: Review of poly (ADP-ribose) polymerase (PARP) mechanisms of action and rationale for targeting in cancer and other diseases. Crit Rev Eukaryot Gene Expr 24(1): 15-28, 2014. PMID: 24579667. DOI: 10.1615/critreveukaryotgeneexpr.2013006875

11 Skidmore CJ, Davies MI, Goodwin PM, Halldorsson H, Lewis PJ, Shall S and Zia'ee AA: The involvement of poly(ADPribose) polymerase in the degradation of NAD caused by gamma-radiation and N-methyl-N-nitrosourea. Eur J Biochem 101(1): 135-142, 1979. PMID: 228934. DOI: 10.1111/j.14321033.1979.tb04225.x

12 Rouleau M, Patel A, Hendzel MJ, Kaufmann SH and Poirier GG: PARP inhibition: PARP1 and beyond. Nat Rev Cancer 10(4): 293-301, 2010. PMID: 20200537. DOI: 10.1038/nrc2812

13 D'Amours D, Desnoyers S, D'Silva I and Poirier GG: Poly(ADPribosyl)ation reactions in the regulation of nuclear functions. Biochem J 342(Pt 2): 249-268, 1999. PMID: 10455009.

14 Chen A: PARP inhibitors: its role in treatment of cancer. Chinese J Cancer 30(7): 463-471, 2011. PMID: 21718592. DOI: $10.5732 /$ cjc. 011.10111

15 Virág L and Szabó C: The therapeutic potential of poly(ADPribose) polymerase inhibitors. Pharmacol Rev 54(3): 375-429, 2002. PMID: 12223530. DOI: 10.1124/pr.54.3.375

16 Flohr C, Bürkle A, Radicella JP and Epe B: Poly(ADPribosyl)ation accelerates DNA repair in a pathway dependent on Cockayne syndrome B protein. Nucleic Acids Res 31(18): 53325337, 2003. PMID: 12954769. DOI: 10.1093/nar/gkg715

17 de Murcia JM, Niedergang C, Trucco C, Ricoul M, Dutrillaux B, Mark M, Oliver FJ, Masson M, Dierich A, LeMeur M, Walztinger C, Chambon P and de Murica G: Requirement of poly(ADP-ribose) polymerase in recovery from DNA damage in mice and in cells. Proc Natl Acad Sci USA 94(14): 7303-7307, 1997. PMID: 9207086. DOI: 10.1073/pnas.94.14.7303

18 Jacobson EL, Smith JY, Wielckens K, Hilz H and Jacobson MK: Cellular recovery of dividing and confluent C3H10T1/2 cells from $\mathrm{N}$-methyl-N'-nitro-N-nitrosoguanidine in the presence of ADP-ribosylation inhibitors. Carcinogenesis 6(5): 715-718, 1985. PMID: 2988808. DOI: 10.1093/carcin/6.5.715

19 Robinson D, Van Allen EM, Wu YM, Schultz N, Lonigro RJ, Mosquera JM, Montgomery B, Taplin ME, Pritchard CC, Attard G, Beltran H, Abida W, Bradley RK, Vinson J, Cao X, Vats P, Kunju LP, Hussain M, Feng FY, Tomlins SA, Cooney KA, Smith DC, Brennan C, Siddiqui J, Mehra R, Chen Y, Rathkopf DE, Morris MJ, Solomon SB, Durack JC, Reuter VE, Gopalan A, Gao J, Loda M, Lis RT, Bowden M, Balk SP, Gaviola G, Sougnez C, Gupta M, Yu EY, Mostaghel EA, Cheng HH, Mulcahy H, True LD, Plymate SR, Dvinge H, Ferraldeschi R, Flohr P, Miranda S, Zafeiriou Z, Tunariu N, Mateo J, Perez-Lopez R, Demichelis F, Robinson BD, Schiffman M, Nanus DM, Tagawa ST, Sigaras A, Eng KW, Elemento O, Sboner A, Heath EI, Scher HI, Pienta KJ, Kantoff P, de Bono JS, Rubin MA, Nelson PS, Garraway LA,
Sawyers CL and Chinnaiyan AM: Integrative clinical genomics of advanced prostate cancer. Cell 161(5): 1215-1228, 2015. PMID: 26000489. DOI: 10.1016/j.cell.2015.05.001

20 Castro E, Goh C, Olmos D, Saunders Ed, Leongamornlert D, Tymrakiewicz M, Mahmud N, Dadaev T, Govindasami K, Guy M, Sawyer E, Wilkinson R, Ardern-Jones A, Ellis S, Frost D, Peock S, Evans DG, Tischkowitz M, Cole T, Davidson R, Eccles D, Brewer C, Douglas F, Porteous ME, Donaldson A, Dorkins H, Izatt L, Cook J, Hodgson S, Kennedy MJ, Side LE, Eason J, Murray A, Antoniou AC, Easton DF, Kote-Jarai Z and Eeles R: Germline BRCA mutations are associated with higher risk of nodal involvement, distant metastasis, and poor survival outcomes in prostate cancer. J Clin Oncol 31(14): 1748-1757, 2013. PMID: 23569316. DOI: 10.1200/JCO.2012.43.1882

21 Mendes-Pereira AM, Martin SA, Brough R, McCarthy A, Taylor JR, Kim J, Waldman T, Lord CJ and Ashworth A: Synthetic lethal targeting of PTEN mutant cells with PARP inhibitors. EMBO Mol Med 1(6-7): 315-322, 2009. PMID: 20049735. DOI: $10.1002 / \mathrm{emmm} .200900041$

22 BRCA1 gene - Genetics Home Reference - NIH. U.S. National Library of Medicine. August 17, 2020. Available at: https://medlineplus.gov/genetics/gene/brca1/\#: :text=Normal\%2 0Function [Last accessed August 30, 2020]

23 Wen WX and Leong CO: Association of BRCA1- and BRCA2deficiency with mutation burden, expression of PD-L1/PD-1, immune infiltrates, and $\mathrm{T}$ cell-inflamed signature in breast cancer. PLoS One 14(4): e0215381, 2019. PMID: 31022191. DOI: 10.1371 /journal.pone.0215381

24 Mersch J, Jackson MA, Park M, Nebgen D, Peterson SK, Singletary C, Arun BK and Litton JK: Cancers associated with BRCA1 and BRCA2 mutations other than breast and ovarian Cancer 121(2): 269-275, 2015. PMID: 25224030. DOI: 10.1002/ cncr.29041

25 Curtin NJ and Szabo C: Therapeutic applications of PARP inhibitors: anticancer therapy and beyond. Mol Aspects Med 34(6): 1217-1256, 2013. PMID: 23370117. DOI: 10.1016/j.mam.2013.01.006

26 Moore K, Colombo N, Scambia G, Kim B, Oaknin A, Friedlander M, Lisyanskaya A, Floquet A, Leary A, Sonke GS, Gourley C, Banerjee S, Oza A, González-Martín A, Aghajanian C, Bradley W, Mathews C, Liu J, Lowe ES, Bloomfield R and DiSilvestro P: Maintenance olaparib in patients with newly diagnosed advanced ovarian cancer. N Engl J Med 379(26): 2495-2505, 2018. PMID: 30345884. DOI: 10.1056/NEJMoa1810858

27 Abida W, Campbell D, Patnaik A, Sautois B, Shapiro J, Vogelzang NJ, Bryce AH, McDermott R, Ricci F, Rowe J, Zhang J, Simmons AD, Despain D, Dowson M, Golsorkhi T and Chowdhury S: Preliminary results from the TRITON2 study of rucaparib in patients (pts) with DNA damage repair (DDR)deficient metastatic castration-resistant prostate cancer (mCRPC): Updated analyses. Ann Oncol 30(5): v327-v328, 2019. DOI: $10.1093 /$ annonc/mdz248.003

28 Astor L: FDA Approves rucaparib for BRCA1/2-mutant mCRPC. Targeted Oncology. May 15, 2020. Available at: https://www.targetedonc.com/view/fda-approves-rucaparib-forbrca1-2-mutant-mcrpc [Last accessed August 8, 2020]

29 With Two FDA Approvals, Prostate Cancer Treatment Enters the PARP Era. National Cancer Institute. June 11, 2020. Available at: https://www.cancer.gov/news-events/cancer-currentsblog/2020/fda-olaparib-rucaparib-prostate-cancer [Last accessed August 30, 2020] 
30 Bono J, Mateo J, Fizazi K, Saad F, Shore N, Sandhu S, Chi KN, Sartor O, Agarwal N, Olmos D, Thiery-Vuillemin A, Twardowski P, Mehra N, Goessl C, Kang J, Burgents J, Wu W, Kohlmann A, Adelman CA and Hussain M: Olaparib for Metastatic CastrationResistant Prostate Cancer. N Engl J Med 382(22): 2091-2102, 2020. PMID: 32343890. DOI: 10.1056/NEJMoa1911440

31 Mateo J, Porta N, Bianchini D, McGovern U, Elliott T, Jones R, Syndikus I, Ralph C, Jain S, Varughese M, Parikh O, Crabb S, Robinson A, McLaren D, Birtle A, Tanguay J, Miranda S, Figueiredo I, Seed G, Bertan C, Flohr P, Ebbs B, Rescigno P, Fowler G, Ferreira A, Riisnaes R, Pereira R, Curcean A, Chandler R, Clarke M, Gurel B, Crespo M, Rodrigues DN, Sandhu S, Espinasse A, Chatfield P, Tunariu N, Yuan W, Hall E, Carreira S, and de Bono JS: Olaparib in patients with metastatic castration-resistant prostate cancer with DNA repair gene aberrations (TOPARP-B): a multicentre, open-label, randomised, phase 2 trial. Lancet Oncol 21(1): 162-174, 2020. DOI: 10.1016/s1470-2045(19)30684-9

32 An efficacy and safety study of niraparib in men with metastatic castration-resistant prostate cancer and DNA-repair anomalies. National Library of Medicine. August 3, 2016. Available at: https://clinicaltrials.gov/ct2/show/NCT02854436 [Last accessed August 30, 2020]
33 Goodman A: PARP inhibitors moving ahead in prostate cancer. PARP inhibitors moving ahead in prostate cancer - The ASCO Post. March 25, 2019. Available at: https://ascopost.com/issues/march25-2019/parp-inhibitors-moving-ahead-in-prostate-cancer/ [Last accessed August 11, 2020]

34 Smith M, Sandhu S, Kelly W, Scher H, Efstathiou E, Lara P, Yu E, George D, Chi K, Saad F, Summa J, Freedman J, Mason G, Zhu E, Ricci D, Simon J, Cheng S and Fizazi K: Pre-specified interim analysis of GALAHAD: A phase II study of niraparib in patients (pts) with metastatic castration-resistant prostate cancer (mCRPC) and biallelic DNA-repair gene defects (DRD). Ann Oncol 30(5): v884-v885, 2019. DOI: 10.1093/annonc/mdz394.043

Received December 11, 2020

Revised December 30, 2020

Accepted December 31, 2020 